\title{
Successes, Challenges and Lessons Learned in Accelerating Introduction of Rotavirus Immunisation in Zambia
}

\author{
Roma Chilengi ${ }^{1,2^{*}}$, Cheryl Rudd ${ }^{1,2}$, Carolyn Bolton ${ }^{1,2}$, Bradford Guffey ${ }^{1,3}$, \\ Penelope Kalesha Masumbu ${ }^{4}$, Jeffrey Stringer ${ }^{2}$ \\ ${ }^{1}$ Centre for Infectious Disease Research in Lusaka, Lusaka, Zambia \\ ${ }^{2}$ University of North Carolina at Chapel Hill, Chapel Hill, USA \\ ${ }^{3}$ University of Alabama at Birmingham, Birmingham, USA \\ ${ }^{4}$ Ministry of Health, Lusaka, Zambia \\ Email: ${ }^{*}$ Roma.Chilengi@cidrz.org
}

Received 6 January 2015; accepted 22 January 2015; published 26 January 2015

Copyright (C) 2015 by authors and Scientific Research Publishing Inc.

This work is licensed under the Creative Commons Attribution International License (CC BY). http://creativecommons.org/licenses/by/4.0/

(c) (i) Open Access

\section{Abstract}

Introduction: Under five mortality in Zambia is unacceptably high and diarrhoea is the third leading contributor. The Programme for Awareness and Elimination of Diarrhoea (PAED) sought to support the government to accelerate the introduction of new vaccines, including the pneumococcal, second dose measles and rotavirus vaccines in Zambia. Here we present our approach, progress and lessons learned in two years of the programme. Stakeholder Engagement: Definite commitment and buy-in and sign off by the MOH were fundamental pre-requisites. National and international stakeholders including the Inter Agency Coordinating Committee (ICC), GAVI Alliance, WHO, University Teaching Hospital, Paediatrics Association of Zambia, and UNICEF were engaged for stakeholder buy-in and integration. Progress made: Following successful integration, PAED was officially launched in January 2012. Preparatory work done included: Introduction and acceptance of the PAED agenda in ICC, new vaccines proposal to GAVI, resource mobilisation, Effective Vaccine Management implementation, national cold chain scale-up strategy, vaccine orientation and adapted data collection tools, health worker training, step-wise vaccine introduction to Lusaka province districts and finally national roll-out of the rotavirus vaccine immunisation. Between January 2011 and November 2013, over 270,000 vaccine doses were distributed in Lusaka province. When 94,500 infants were fully immunised, adequate preparations had been made to facilitate national launch of rotavirus immunisations countrywide on 27th November 2013. Discussion: The PAED model was successful at resource mobilization; it has demonstrated how private sector can contribute to new vaccine introduction. Lessons learned from this model can be replicated in other countries with similar need and constraints.

\footnotetext{
${ }^{*}$ Corresponding author.
}

How to cite this paper: Chilengi, R., Rudd, C., Bolton, C., Guffey, B., Masumbu, P.K. and Stringer, J. (2015) Successes, Challenges and Lessons Learned in Accelerating Introduction of Rotavirus Immunisation in Zambia. World Journal of Vaccines, 5, 43-53. http://dx.doi.org/10.4236/wjv.2015.51006 


\section{Keywords}

\section{Zambia, Rotavirus Vaccines, Introduction, Cold Chain}

\section{Introduction}

\subsection{Rotavirus}

Rotavirus (Figure 1) is a double stranded RNA virus belonging to the family of Reoviridae. Rotavirus kills half a million children each year worldwide including approximately 230,000 children in sub-Saharan Africa [1]-[3]. In Zambia, children under 5 years of age experience 10 million annual episodes of diarrhoea, which result in an estimated 63,000 hospitalizations and 15,000 deaths [4]. This makes diarrhoea Zambia's third leading cause of under-5 mortality (after pneumonia and malaria). One-quarter to one-third of the severe diarrhoea resulting in hospitalization and death are attributable to vaccine-preventable rotavirus [5] [6]. These statistics are recorded in spite of the infection being vaccine preventable with two already licensed vaccines.

\subsection{Why Accelerate New Vaccine Introductions?}

Immunisation is one of the safest and most cost-effective ways to reduce disease and prevent death [6]-[10]. Historically, vaccination has proved to be a highly effective approach to controlling infectious diseases and many believe that it will not be possible to move from control to disease elimination without the use of vaccines [7] [8]. Following the success of the smallpox eradication campaigns in the 1980's, efforts to combat other major diseases including diphtheria, pertussis, tetanus, polio, hepatitis, haemophilus influenza and measles have transpired over the past 20 years. These vaccines are estimated to save 3 million lives each year and prevent long-term illness and disability [7]. However, it is a well-known fact, and unfortunately widely accepted, that new life saving vaccines can take 15 - 20 years to reach those who need them in developing countries [11]. The world is far from achieving vaccine equity—ready access to vaccines by all who need them—and according to the Global Alliance on Vaccine Initiative (Gavi) over 19 million of the world's poorest children still do not receive basic life-saving vaccines [12].

\subsection{The PAED Programme}

The Programme for Awareness and Elimination of Diarrhoea (PAED), is a collaborative effort that was initiated by the Centre for Infectious Disease Research in Zambia (CIDRZ) and Absolute Return for Kids (ARK), work-

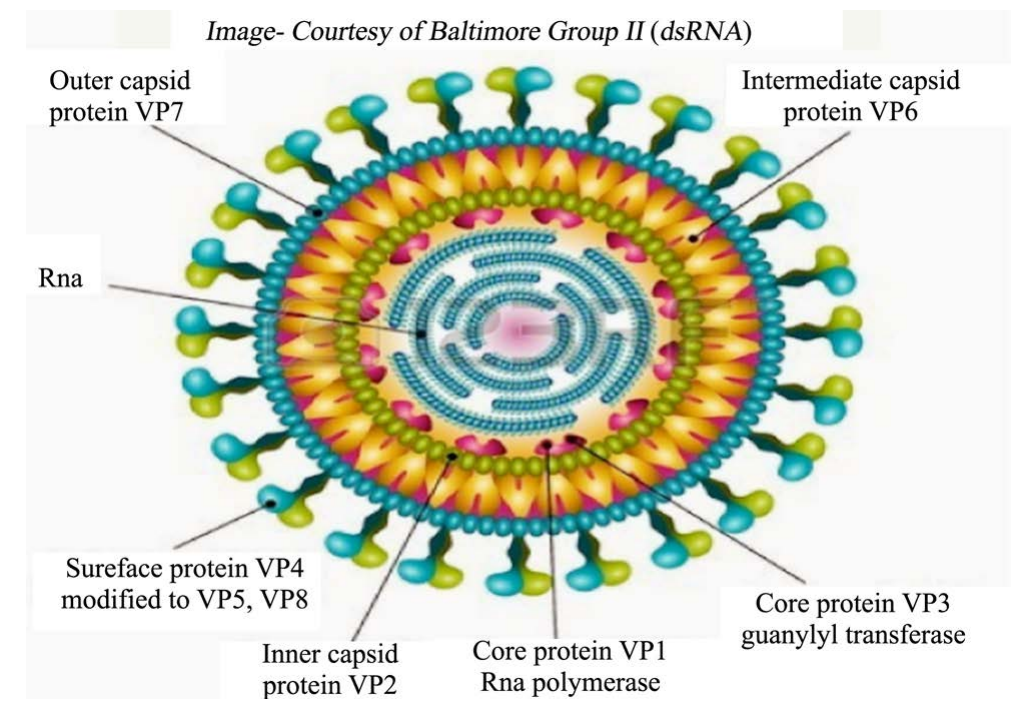

Figure 1. Structural illustration of Rotavirus. 
ing in partnership with the Zambian Ministry of Health $(\mathrm{MoH})$ and the Ministry of Community Development, Mother and Child Health, as well as with other key stakeholders to jump-start and build momentum for control of diarrhoea as a critically neglected disease. The programme has two overarching goals:

1. To reduce under-5 mortality in the Lusaka Province through the introduction of a comprehensive diarrhoea control programme that includes rotavirus vaccination through the national immunisation programme, improved clinical care, and community action; and

2. To accelerate the country-wide introduction of rotavirus vaccination and other high-priority childhood vaccines in Zambia through strategic investments in cold chain, commodities management, policy and protocol development, planning, and advocacy.

This paper describes the experiences, opportunities and lessons learned in the process of incorporation and introduction of the rotavirus vaccine into the Zambia EPI.

\section{Methodology}

\subsection{Establishing Critical Partnerships}

Integrating PAED into the MoH was of utmost importance. Thus a detailed implementation plan was initially reviewed and approved by the Permanent Secretary in the Ministry of Health.

With that, PAED's work became a part of the regular agenda within the MoH Child Health Unit (CHU) and specific National Technical Working Groups (TWG).

\subsection{The PAED Strategy}

PAED adopted the United Nations Children's Fund (UNICEF)/World Health Organisation (WHO) seven-point recommended strategy for fighting diarrhoea [13]. With guidance from the MoH, PAED focused on implementing some of the recommended strategies for which there was a realistic possibility to have impact while advocating for the others (i.e. Vitamin A supplementation which is already successful, improved drinking water supply and community-wide sanitation for which PAED had no capacity to impact). As shown in Table 1, PAED focused on introduction of therotavirus and other childhood vaccines; appropriate treatment of diarrhoea with low-osmolarity Oral Rehydration Salts (ORS) and zinc, hand washing with soap, and promotion of exclusive breast feeding. Based on existing literature and an assessment of feasibility, specific assumptions were taken as to what can be achieved through the PAED Interventions.

To address impact the Bill and Melinda Gates Foundation funded evaluation and cost effectiveness assessment through a stand-alone project-A Comprehensive Assessment of Diarrhoea and Enteric Disease Management in Children (ACADEMIC).

\subsection{The Setup}

PAED rapidly evolved into a complex network of activities with multiple partners as summarised in Figure 2. Generally, WHO and UNICEF country offices provide supply and cold chain, logistics management and other vaccine related technical support. Other international development agencies that are traditional stakeholders include the Japanese International Cooperation Agency (JICA) and the Canadian International Development Agency (CIDA).

Table 1. Paed interventions, target coverage and potential impact after 3 years.

\begin{tabular}{|c|c|c|c|}
\hline Interventions & Initial Coverage & $\begin{array}{c}\text { Coverage } \\
\text { Target }\end{array}$ & Potential Impact \\
\hline Rotavirus vaccine introduction into national EPI & $0 \%$ & $90 \%$ & $\begin{array}{l}\text { 24\% mortality reduction; } 61 \% \\
\text { efficacy at reducing severe } \\
\text { diarrhoea }\end{array}$ \\
\hline $\begin{array}{l}\text { Improved case management of diarrhea including use of: } \\
\begin{aligned} \bullet \quad \text { Low-osmolarity ORS } \\
\bullet \quad \text { Zinc }\end{aligned}\end{array}$ & $\begin{array}{l}\text { ORS } 53 \% \\
\text { Zinc: No data; } \\
\quad \sim 0 \%\end{array}$ & $\begin{array}{l}\text { ORS } 75 \% \\
\text { Zinc } 40 \%\end{array}$ & $\begin{array}{l}\text { Mortality reduction: } \\
\text { ORS } 93 \% \\
\text { Zinc } 23 \%\end{array}$ \\
\hline Hand washing with soap & Limited data; 20\% & $30 \%$ & $48 \%$ reduction in mortality \\
\hline Exclusive breastfeeding promotion & $35 \%$ & $65 \%$ & 3.5-fold risk reduction \\
\hline
\end{tabular}




\section{Partners in PAED}

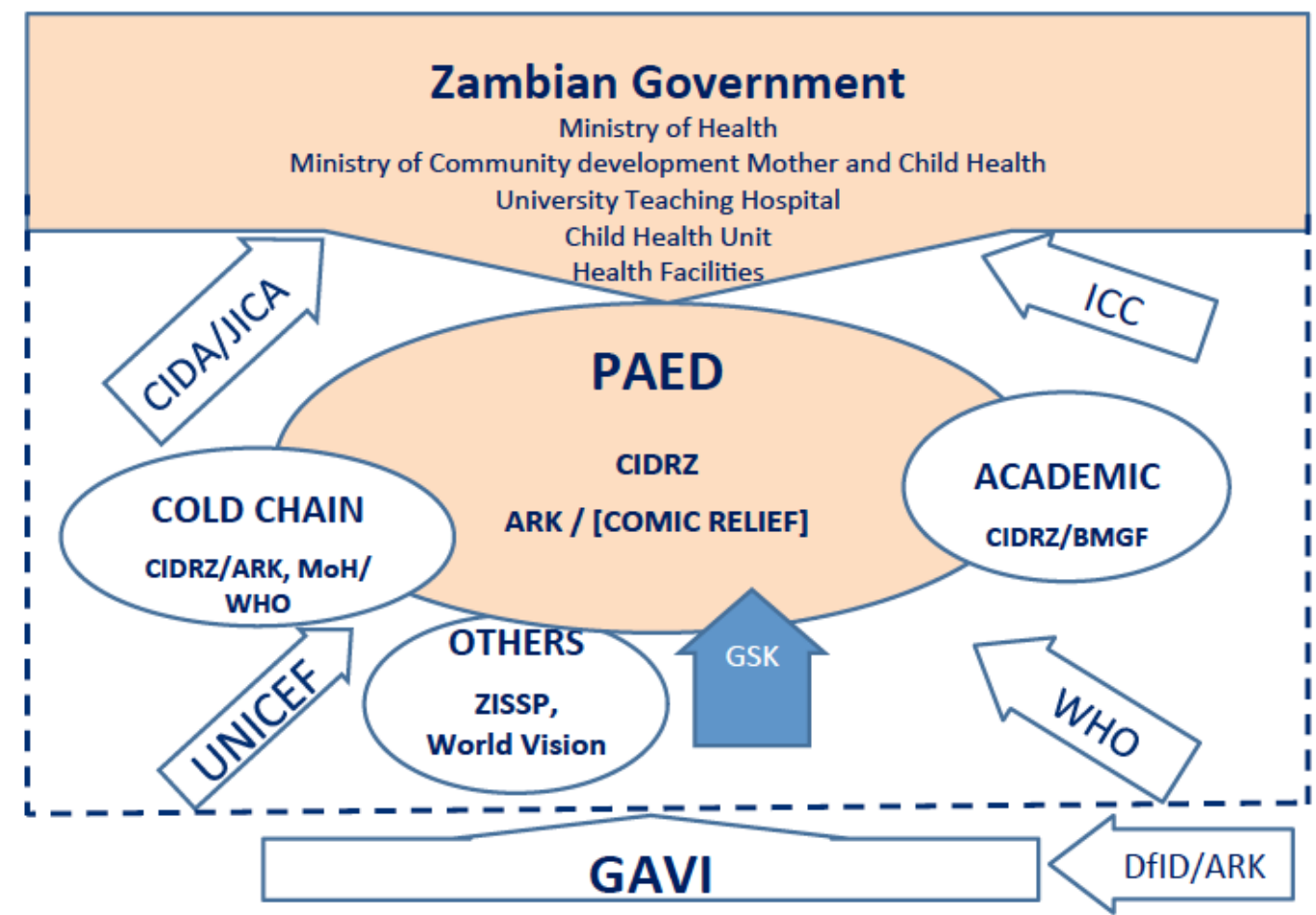

Figure 2. PAED Partnerships. Abbreviations: ARK—Absolute Return for Kids, UK; BMGF-Bill and Melinda Gates Foundation; CIDRZ_-Centre for Infectious Disease Research in Zambia; DfID_Department for International Development, UK; DHMT_-District Health Management Team; GAVI_Global Alliance on Vaccine Initiative; GSK-Glaxo Smithkline; ICC-Inter Agency Coordinating Committee; JICA-Japanese International Development Agency; PMO_Provincial Medical Office; UNICEF-United Nations Children Fund; WHO_-World Health Organisation; ZISSP_Zambia Institutional Systems Strengthening Project.

\subsection{Gavi-The Vaccine Alliance Requirements for National Support}

Cardinal Gavi requirements that needed to be satisfied in order to access support for new vaccines include:

1. Having a functional Interagency Coordination Committee (ICC) focused on immunisation (or an equivalent collaborative mechanism) for local coordination and accountability;

2. A recent Effective Vaccine Management (EVM) assessment report together with an improvement; and

3. A detailed, comprehensive multi-year plan for immunisation, including plans for sustaining immunisation activities after Gavi support is terminated.

The ICC was already function in gat PAED's inception. For the second condition, PAED partnered with MoH, UNICEF and WHO to fund EVM assessment and report. The EVM assessed the status of the country's vaccine management, scoringon nine categories: vaccine arrival; temperature; storage capacity; buildings, equipment and transport; maintenance; stock management; distribution; vaccine management; and management information systems and supportive functions. Findings of the assessment fed into a national improvement plan. Key areas highlighted for improvement were:

- Increased cold chain capacity;

- Improved temperature monitoring with the use of continuous temperature recorders;

- Better stock management to avoid stock outs;

- Development and use of a vaccine distribution management plan; and

- Additional training and supportive supervision to improve vaccine management.

\subsection{Resource Mobilization}

Absolute Return for Kids-ARK provided the initial seed funding for PAED activities with a grant of \$2.8 mil- 
lion. The ARK funding also offered an additional \$2.8 million on condition that the project leverages other funding for PAED, which would be matched dollar for dollar, up to that maximum. Figure 3 depicts the PAED progress with resource mobilization.

Beginning with a complete buy-in and ownership of the project, the Ministry of health committed to $\$ 225,000$ to refurbish and upgrade cold chain central infrastructure. The PAED evaluation project earlier described as ACADEMIC attracted a \$3.8 million grant from the Bill and Melinda Gates Foundation. With this, the ARK match condition was at that point satisfied and thus unlocked the $\$ 2.8$ million offer. The project further lobbied to the GlaxoSmithKline (GSK) as manufacturer of Rotarix ${ }^{\mathrm{TM}}$, which was the vaccine of choice. While PAED had budgeted for purchasing sufficient vaccines for the entire provincial birth cohort for two years, GSK's free donation of over 304,000 vaccine doses freed up \$1.3 m budgeted for vaccine procurement. Taking advantage of the vaccine introduction into the routine imminization schedule, the PAED Director was awarded an R01 grant by the United States National Institutes of Health $(\mathrm{NiH})$ to study potential factors that may contribute to lowered vaccine efficacy in Zambia as reported in other developing country settings; this is a five year grant of \$670,000. Further, Comic Relief, a UK based charity became interested the project and provided support for developing a comprehensive behaviour change component targeting hand washing with soap, exclusive breastfeeding and promotion of oral rehydration salts and zinc for treating diarrhoea. This later effort resulted in a supplementary grant of \$1.6 m. Lastly, realizing the critical importance of water and sanitation, UNICEF awarded PAED a grant of $\$ 770,000$ to specifically support coordination of community led total sanitation and schools WASH project in two of the rural districts where the programme operates. In essence, what began as a modest $\$ 2.8 \mathrm{~m}$ project has, over a space of three years, grown into a multi-million-dollar endaevour with definite long-term plans.

\subsection{International Advocacy and Leveraging}

Preparations for the PAED project coincided with the global push towards making vaccines more available. In January 2010, Bill and Melinda Gates announced that their foundation would commit US\$10 billion over the

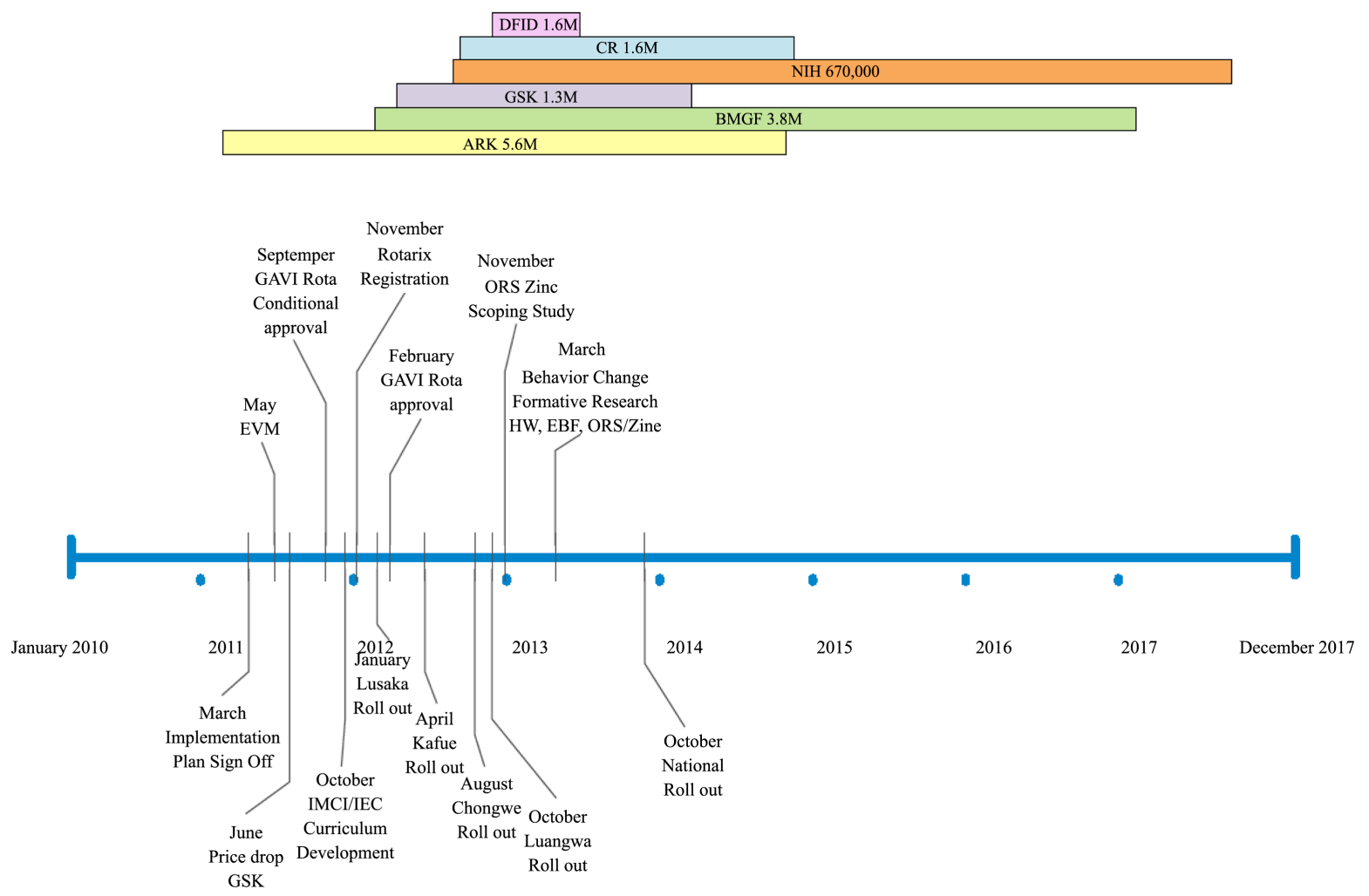

Figure 3. PAED timelines and funding achievements. Acronyms: UNICEF-United Nations Children's Fund; DfID—Department for International Development; CR—Comic Relief; NiH—National Institutes of Health; GSK—GlaxoSmithKline; BMGF_Bill and Melinda Gates Foundation; ARK—Absolute Return for Kids. 
next 10 years to aid research in vaccines, and to develop and deliver vaccines for the world's poorest countries. As the timelines to the Millennium Development Goals target drew nearer, in 2011, Gavi also committed US $\$ 4.3$ bn to scale up immunisation programmes. Other global pushes included the UK Aid Match launched in June 2011, which was a demand-led fund through which the United Kingdom Department for International Development (DfID) would match public donations to appeals for development activities focused on poverty reduction in developing countries. PAED took advantage of this opportunity and committed £1 million for DfID to match and earmarked it for Gavi once Zambia was supported for national introduction of rotavirus immunization.

During 2012, GSK also officially announced price reductions on Rotarix ${ }^{\mathrm{TM}}$ for Gavi-eligible countries from the anticipated \$16 per child immunized to only \$5 (or \$2.5 per dose). For PAED, this over 67\% reduction in price meant that at least two more children (over and above each budgeted child) could then be vaccinated with the allocated funds for rotavirus vaccine in the budget.

\subsection{Addressing Cold Chain Capacity}

Based on World Health Organisation's recommended Effective Vaccine Management (EVM) improvement plan and prior feedback from Gavi, the country embarked on addressing current gaps in cold chain infrastructure at each level (National, Provincial, District and Health Facility). The ICC, the MoH and partners had the task address gaps in the cold chain in order to meet Gavi requirements. Figure 4 shows the projected impact of additional cold storage space required with the introduction of new vaccines and population growth.

A national cold chain scale-up strategy was developed based on the identified gaps to assist in thmoblisation of funds and to create transparency of the national cold chain needs and were quantified in monetary terms. Table 2 shows the state of acomplishment as of October 2013. Following regular progress updates to the Gavi, a decision was reached by June 2012 to award Zambia an unconditional approval for a grant to support new vaccines introduction nationally starting with the pneumococcal, second dose measles and rotavirus vaccines. The real achievement here is that at the National level, Zambia expanded its cold storage capacity for vaccines from 144 to 212,000 litres sufficient to carter to national needs for the coming decade.

\subsection{Opportunity for the PAED Pilot Demonstration in Lusaka Province}

While the Zambian government was enthusiastic to see new vaccines, including the rotavirus antigen introduced into the country, national introduction of three new vaccines in a developing world setting was unprecedented.

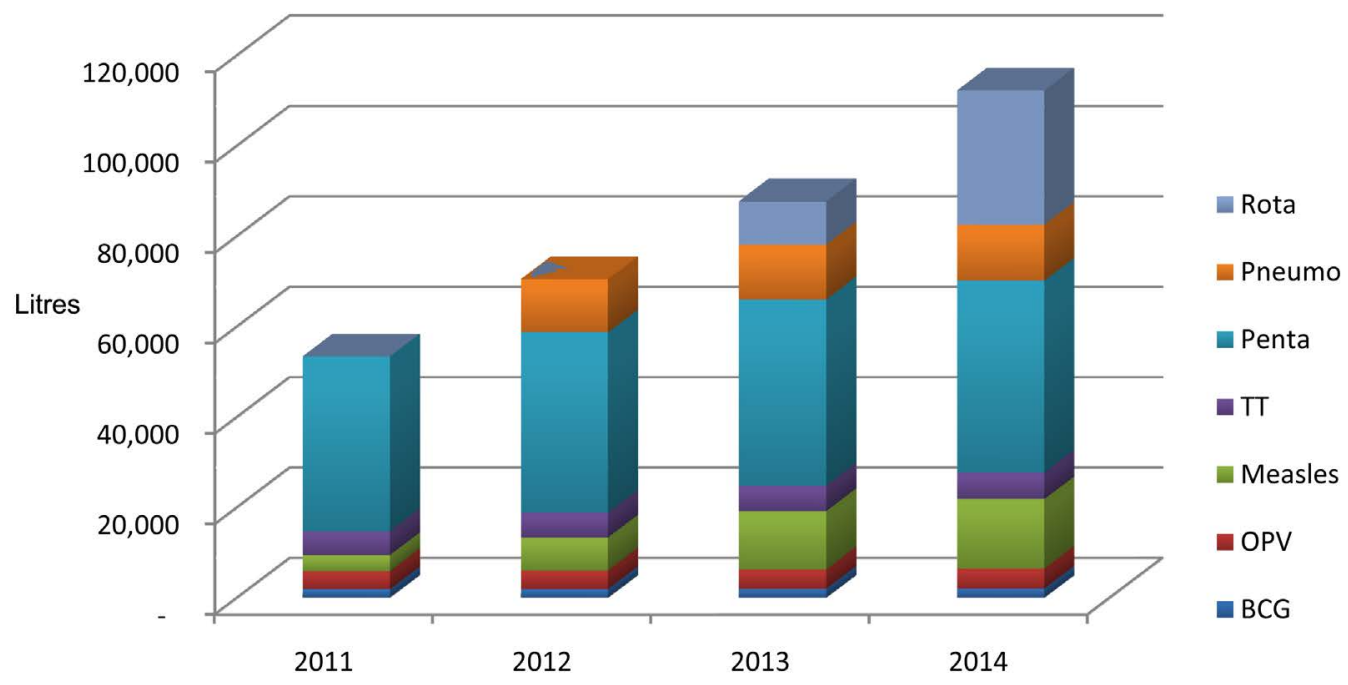

Figure 4. Projected Increased Cold Chain Capacity Requirements for New Vaccines. Acronyms: Rota-Rotarix; Pneumo-10 valent-Pneumococcal Conjugate vaccine; Penta-Pentavalent vaccine containing Diptheria, Petusiss, Infant tetanus, haemophilus influenza, and hepatitis B vaccines; TT-Tetenus Toxoid ; OPV-Oral polio; and BCG-Bacillus Calmette-Guérin. 
Table 2. Cold Chain Status as at October 2013.

\begin{tabular}{cccc}
\hline \multicolumn{3}{c}{ Positive Cold Chain Capacity in Litres } \\
\hline Level & Original Capacity & Mobilised Capacity & Remaining Capacity Required \\
\hline National & 10,000 & 47,619 & 0 \\
Provincial & 7778 & 36,038 & 7143 \\
District & 19,008 & 1440 & $(1$ cold room $)$ \\
672 \\
Health Facility & 33,600 & 1704 & (Estimated 28 new districts) \\
18,000 \\
(Estimated 750 refrigerators)
\end{tabular}

\begin{tabular}{cccc}
\hline & \multicolumn{2}{c}{ Cold Chain Funding for Expansion (USD) } \\
\hline Level & Funds Required & Funds Mobilised & Remaining \\
\hline National & $\$ 1,028,500$ & $\$ 908,500$ & $\$ 120,000$ \\
Provincial & $\$ 545,000$ & $\$ 310,500$ & $\$ 234,500$ \\
District & $\$ 155,500$ & $\$ 148,000$ & $\$ 7500$ \\
Health Facility & $\$ 2,011,000$ & $\$ 61,000$ & Approx. $\$ 1,950,000$ \\
Total & $\$ 3,740,000$ & $\$ 1,428,000$ & $\$ 2,312,000$ \\
\hline
\end{tabular}

The Gavi approved plan was to introduce the vaccines starting with pneumococcal and second dose measles vaccines in 2012 and 2013 and then rotavirus vaccine later, likely around 2015.

While this was encouraging, it was ever important to note that as many as 30,000 children may die from diarrhoea-related causes in the interim (i.e., between 2012 and 2014) before the rotavirus vaccine would be introduced with the existing levels of care continued [4]. Thus PAED pilot was highly appealing-introduce rotavirus vaccine in the most populated province as a demonstration project ahead of the scheduled national introduction. The PAED project was therefore set to help develop the necessary tools and introductory mechanisms, generate experience with the vaccine, assess cost and vaccine effectiveness and impact in one province-paving the way for national rollout. Thus, on $20^{\text {th }}$ January 2012, the Honourable Minister of Community Development, Mother and Child Health, officially launched PAED interventions and personally administered the first dose of rotavirus vaccine on $23^{\text {rd }}$ January in Lusaka District. PAED was rolled out to the other three districts of Lusaka Province in a step-wise manner over the year as follows: Kafue district on $19^{\text {th }}$ April 2012; Chongwe district on $23^{\text {rd }}$ July 2012 and finally to Luangwa District on $22^{\text {nd }}$ October 2012.

\subsection{Which Rotavirus Vaccine?}

Two orally administered, live, attenuated rotavirus vaccines are currently licensed and available on the market, both of which are WHO pre-qualified for use in developing countries.

The monovalent rotavirus vaccine (Rotarix ${ }^{\mathrm{TM}}$ manufactured by Glaxo Smith Kline Biologicals) contains the RIX4414 rotavirus strain developed from attenuation of a human strain (G1P [8]) [13] [14]. This vaccine requires two doses to complete the schedule and these have been evaluated in a variety of schedule options to confirm that it can correspond to the timing of giving the first and second doses of oral polio vaccine (OPV) and diphtheria-tetanus-pertussis (DTP)-containing vaccines [15]. The second vaccine is the pentavalent rotavirus vaccine (RotaTeq ${ }^{\mathrm{TM}}$ manufactured by Merck and Co.) and is derived from the re-assortment of human rotavirus strains with bovine strains. The five re-assortant rotaviruses express one of the outer capsid proteins (G1, G2, G3, G4, or P1A [8]) from human rotavirus strains [16]. This vaccine requires three doses to complete the schedule and can also be co-administered with OPV and DPT vaccines [17].

To make a decision on which vaccine to introduce in Zambia, the ICC constituted a task force that reviewed literature, considered available data on sero-epidemiology of rotavirus in Zambia [5] [18] [19], efficacy from African clinical trials [20] [21], and cold chain and other logistical requirements. Table 3 summarises the key 
Table 3. Comparison of available rotavirus vaccines for decision making on which vaccine to introduce in Zambia.

\begin{tabular}{|c|c|c|}
\hline Attribute & Rotarix & Rotateq \\
\hline Manufacturer & GlaxoSmithKline & Merck \\
\hline No. of doses per fully immunized child & 2 & 3 \\
\hline No. of doses per vial & 1 & 1 \\
\hline Vaccine Vial Monitor Type & On cap & None \\
\hline Upper age limit (per manufacturers guide) & 24 weeks & 32 weeks \\
\hline Efficacy in African trials & $\begin{array}{c}\text { 72.2\% (South Africa) } \\
\text { 49.2\% (Malawi) }\end{array}$ & $\begin{array}{c}\text { 63.9\% (Kenya) } \\
55.5 \% \text { (Ghana) } \\
\text { 17.6\% (Mali) }\end{array}$ \\
\hline Rotavirus strains covered & G1, G3, G4, G9 & G1, G2, G3, G4, P1 \\
\hline Min. storage volume per dose $\left(\mathrm{cm}^{3}\right)$ & 17.1 & 45.9 \\
\hline Minimun storage volume per fully immunized child $\left(\mathrm{cm}^{3}\right)$ & 34.2 & 137.7 \\
\hline Largest pack size & 50 & 25 \\
\hline
\end{tabular}

findings upon which a decision was made to choose the rotavirus vaccine. Given a similar efficacy range, cold chain requirements were more heavily weighted in favour of Rotarix ${ }^{\mathrm{TM}}$, which requires a third of storage space when compared to RotaTeq ${ }^{\mathrm{TM}}[22]$.

\section{Challenges and Lessons Learned}

Integration and Sustainability-Expansion of the national immunisation system requires ownership by government and involvement of all stakeholders.

The PAED programme took a year in ensuring that it is appropriately owned and authorised by the Ministry of Health and ensure all traditional partners in child immunisation have buy-in into the programme. This came at a cost in terms of both funding for programme staff and time, but the reward as was smooth national up take. By the close of the year 2013-barely 23 months after the official launch, the programme was well established within the routine public system. Materials and experience to roll-out the vaccine nationally were securely in place by the time 94,500 infants in the pilot province were fully immunised in November 2013.

A critical strength of this programme was its sustainable exit plan; since inceptiona government taken up national roll out was foreseen. A comparable programme in the region is the Human Papiloma Virus (HPV) vaccine pilot introduction in Uganda [23], which was successful, yet tainted with doubts on its national rollout and scalability [24]. The success of PAED seems to be anchored on the fact that sustainable exits plan part of the original programme objectives.

Accurate Documentation for Effectiveness Assessment-There is great need to accurately document what is required and how much it costs to introduce new vaccines in developing countries.

In order to accurately assess the impact and effectiveness of any programme, it is required that correct measurements are taken for the baseline situation of the problem, as well as how the interventions are implemented and progressive assessments over time.

In this case, the baseline evaluation required an accurate account of the diarrhoea problem. Many diarrhoeal cases and deaths may be occurring within the community and these are not captured in the Health Management Information Systems (HMIS) data. Many developing countries including Zambia depend on HMIS data that completely misses events within the community. These data, if used for vaccine impact assessment, would result in incorrect vaccine impact assessment. In order to get an accurate understanding of the disease burden, and eventual vaccine impact, PAED sought separate funding for the impact evaluation project called "ACADEMIC" which was supported to undertake comprehensive community surveys in order to objectively ascertain the impact of PAED. 
Time Pressure Versus Doing It Right—Donor funded programmes tend to have strict time limitations for delivery of results, however, complex projects demand some flexibility.

The initial funding agreement of PAED was for a total period of three years. However, it took over 6 months to clarify PAED implementation plan with the $\mathrm{MoH}$ and to have the Permanent Secretary agree and sign off on the plan. It also took several months to hire, settle in the key staff and establish working relations and links within the governmental and non-governmental child health system and partners. Thus, although the funding Memorandum of Understanding was signed in November 2010, the official launch and rollout of PAED was on $19^{\text {th }}$ January 2012. While this lag time caused much strain on the project, it turned out to be invaluable as it allowed the programme to be established firmly and accepted by all key stakeholders. The lesson here is that planning must include time for understanding the environment in which the programme will operate.

New Vaccines Versus the Stretch on Health Systems-Concurrent vaccine introduction requires enhancement of health systems including pharmacovigilence systems to document adverse events following immunization.

Zambia introduced 3 new vaccines into the national immunisation system between 2012-2013, as well as initiated the HPV vaccine pilot in Lusaka province. It is foreseeable that several more new vaccines that have the potential to save lives, such as the malaria vaccine, are in the research pipeline and will become available over the next decade in many countries within Africa. Although this is desirable, it demands appropriate attention to be given to the health system in order to be able to stretch the capability to deliver these vaccines effectively [25] [26]. Pharmac ovigilance systems also need to be enhanced in order to ensure adequate documentation of any adverse events following immunisations.

Community Engagement-One approach Does not fit all districts for countries like Zambia with diversity in social, cultural and ethnicity.

As PAED rolled-out to new districts, it became evident that specific approaches were needed to engage with the community. While engagement through established neighbourhood health committees remained consistent, it became obvious that each district required specific community engagement strategies. Thus, PAED expanded to include churches and community gatherings, government Community Development Assistants, village chiefs and traditional leadership structures in the repertoire of outreach activities. These community groups and individuals allow PAED's reach to go beyond its initial plans, and speak to the pliable nature of the programme.

Human Resources for Health-Expansion in services require expansion in service providers.

Although health care improvements must come with commensurate increases in the quality and quantity of health care providers, programmes do not usually address the human resource component. Adding new vaccines does not just require more cold chain space; it requires more training and adds to the activities that the already stretched health care providers have to carry.

In the PAED experience, it became apparent that there was a need for additional human resource capacity and technical expertise in the delivery of vaccines throughout the country. The Ministry had planned additions for health care providers, but those plans did not necessarily synchronize with the PAED project. PAED thus hired and seconded a full-time senior logistician position placed at the Ministry to provide technical support on key operational logistics including routine child health supplies, cold chain management and overall EPI logistics. This individual is a key liaison between stakeholders including WHO, UNICEF and others on matters pertaining to logistics. There remains more systemic expansion of health care workers to enhance actual vaccine delivery, community outreach as well as management of data related to immunisation services.

\section{Concluding Remarks}

Whereas PAED at this stage is a resounding success, and the rotavirus vaccine has been rolled-out nationally, it remains to be seen what the overall impact of the project on mortality will be. Indeed, the evaluation surveys are scheduled to take place early in 2015. As of the end of July 2014, a total 187,245 had received one dose and 152,149 children were fully immunised in the pilot area of Lusaka province. It will be important to share the programme impact and cost effectiveness, which will really show how affordable or otherwise the programme has been. Most importantly, it will be critical to review these data in terms of lives saved, which is the important overarching public health goal for such a programme. Greater successes would be scored if this PAED experience can be adopted and used in other countries in the region to accelerate the pace at which new interventions 
are introduced to reach the needy children.

\section{Author's Contributions}

RC lead the work, wrote the first draft, collated all contributions and wrote the final draft; CR managed the project and contributed to the draft; CR, BG, SD and PKS contributed to the conception of the work and reviewed the draft; JS critically revised the manuscript for intellectual content.

\section{Acknowledgements}

We wish to also acknowledge the contributions of the following individuals and organisations: Ben Chi, Beatrice Akatama, Aubrey Musiamo Samwinga, Thandiwe Malambo, Julia Lekezya Simuwelu, Jenala Chipungu, Mercy Mwale, Monde Ndana and Cheri Reid from CIDRZ; Charles Abani, Colin Almeleh, Frank Aswani, Sally Clarke, Samukeliso Dube, Susannah Harresand Maria Neophytou from ARK; Kate Harrison from Comic Relief; Peter Mwaba, Elwyn Chomba, Elizabeth Chizema, Carol Phiri, Josephine Simwinga, Vichael Silavwe, Elicah Kamiji, Charles Zulu and Obert Silwimba from the Zambian Ministries of Health and Community Development Mother and Child Health; Olusegan Babaniyi, Belem Matapo, Abraham Mwanamwenge, and Helen Mutambo from World health Organisation in Zambia; Ngawa Ngoma, Rodgers Mwale and Devika Kapur from UNICEF Zambia.

We also acknowledge Glaxo Smith Kline Biologicals (Belgium) for the kind donation of Rotarix vaccines.

\section{Funding}

This work was funded by the following organisations i) Absolute Return for Kids (ARK-UK), and Comic Relief (UK). The Bill and Melinda Gates Foundation (USA) provided support for monitoring and evaluation. The National Institutes for Health $(\mathrm{NiH})$ are supporting a related research study on exploring potential causes of vaccine failure in Zambia.

\section{Competing Interests}

The authors have no conflict of interest in the work published here.

\section{References}

[1] World Health Organization (2007) Rotavirus Vaccines. Weekly Epidemiological Record, 82, 285-296.

[2] Parashar, U.D., Burton, A., Lanata, C., et al. (2009) Global Mortality Associated with Rotavirus Disease among Children in 2004. The Journal of Infectious Diseases, 200, S9-S15. http://dx.doi.org/10.1086/605025

[3] Parashar, U.D., Gibson, C.J., Bresse, J.S. and Glass, R.I. (2006) Rotavirus and Severe Childhood Diarrhoea. Emerging Infectious Diseases, 12, 304-306. http://dx.doi.org/10.3201/eid1202.050006

[4] ZMOH (2009) Zambia Ministry of Health 2008. Annual Health Statistical Bulletin, 2009.

[5] Steele, A.D., Kasolo, F.C., Bos, P., et al. (1998) Characterization of VP6 Subgroup, VP7 and VP4 Genotype of Rotavirus Strains in Lusaka, Zambia. Annals of Tropical Paediatrics, 18, 111-116.

[6] Mpabalwani, M., Oshitani, H., Kasolo, F., et al. (1995) Rotavirus Gastro-Enteritis in Hospitalized Children with Acute Diarrhoea in Zambia. Annals of Tropical Paediatrics, 15, 39-43.

[7] (2014) Gavi. Value of Immunisation. http://www.gavialliance.org/about/value/

[8] Chilengi, R. and Gitaka, J. (2010) Is Vaccine the Magic Bullet for Malaria Elimination? A Reality Check. Malaria Journal, 9(S3).

[9] (2014) Global Health Research Policy Network. Making Markets for Vaccines—A Practical Plan. http://www.who.int/intellectualproperty/news/en/SubmissionBarder1.pdf

[10] Taylor K., Nguyen A. and Stéphenne J. (2009) The Need for New Vaccines. Vaccine, 27, G3-G8. http://dx.doi.org/10.1016/j.vaccine.2009.10.014

[11] Gavi (2014) Health Equity. www.gavialliance.org/about/value/health-equity/

[12] UNICEF/WHO (2009) Diarrhoea: Why Children Are Still Dying and What Can Be Done. http://www.who.int/maternal_child_adolescent/documents/9789241598415/en/index.html

[13] WHO (2014) Introduction of rotavirus vaccines. Information for Policy Makers, Programme Managers and Health 
Workers.

http://www.who.int/immunization/monitoring_surveillance/burden/vpd/surveillance_type/sentinel/rotavirus_intro_guid ance_who_july31_2013.pdf

[14] GlaxoSmithKline. Rotarix-Electronic Medicines Compendium. http://www.medicines.org.uk/emc/document.aspx?documentId=17840\#PRODUCTINFO

[15] Ruiz-Palacios, G.M., Perez-Schael, I. and Velazquez, F.R. (2006) Safety and Efficacy of an Attenuated Vaccine against Severe Rotavirus Gastroenteritis. New England Journal of Medicine, 354, 11-22. http://dx.doi.org/10.1056/NEJMoa052434

[16] Drug Lib. Com. Rotateq (Rotavirus Vaccine)—Summary. http://www.druglib.com/druginfo/rotateq/

[17] Vesikari, T., Matson, D.O., Dennehy, P., Van Damme, P., Santosham, M., Rodriguez, Z., et al. (2006) Safety and Efficacy of a Pentavalent Human-Bovine (WC3) Reassortant Rotavirus Vaccine. New England Journal of Medicine, 354, 23-33. http://dx.doi.org/10.1056/NEJMoa052664

[18] Mwenda, J.M., Ntoto, K.M., Abebe, A., Enweronu-Laryea, C., Amina, I., Mchomvu, J., et al. (2010) Burden and Epidemiology of Rotavirus Diarrhoea in Selected African Countries: Preliminary Results from the African Rotavirus Surveillance Network. Journal of Infectious Diseases, 202, S5-S11. http://dx.doi.org/10.1086/653557

[19] Levy, K., Hubbard, A.E. and Eisenberg, J.N.S. (2009) Seasonality of Rotavirus Disease in the Tropics: A Systematic Review and Meta-Analysis. International Journal of Epidemiology, 38, 1487-1496. http://dx.doi.org/10.1093/ije/dyn260

[20] Madhi, S.A., Cunliffe, N.A., Steele, D., Witte, D., Kirsten, M., Louw, C., et al. (2010) Effect of Human Rotavirus Vaccine on Severe Diarrhoea in African Infants. New England Journal of Medicine, 362, 289-298. http://dx.doi.org/10.1056/NEJMoa0904797

[21] Armah, G.E., Sow, S.O., Breiman, R.F., Dallas, M.J., Tapia, M.D., Feikin, D.R., et al. (2010) Efficacy of Pentavalent Rotavirus Vaccine against Severe Rotavirus Gastroenteritis in Infants in Developing Countries in Sub-Saharan Africa: A Randomised, Double-Blind, Placebo-Controlled Trial. The Lancet, 376, 606-614. http://dx.doi.org/10.1016/S0140-6736(10)60889-6

[22] Clemens, J. and Jodar, L. (2005) Introducing New Vaccines into Developing Countries: Obstacles, Opportunities and Complexities. Nature Medicine, 11, S12-S15. http://dx.doi.org/10.1038/nm1225

[23] PATH, Vaccine Resource Library (2011) HPV Vaccination in Africa: Lessons Learned From a Pilot Program in Uganda. www.path.org/vaccineresources/details.php?i=1350

[24] Ladner, J., Besson, M.H. and Rodrigues, M. (2014) Performance of 21 HPV Vaccination Programs Implemented in Low and Middle-Income Countries, 2009-2013. BMC Public Health, 14, 670. http://dx.doi.org/10.1186/1471-2458-14-670

[25] Clemens, J. and Jodar, L. (2005) Introducing New Vaccines into Developing Countries: Obstacles, Opportunities and complexities. Nature Medicine, 11, S12-S15. http://dx.doi.org/10.1038/nm1225

[26] WHO (2006) Sixth Global Vaccine Research Forum: Many New Life-Saving Vaccines in Pipeline, but Challenges Persist. www.who.int/mediacentre/news/releases/2005/pr27/en/ 
Scientific Research Publishing (SCIRP) is one of the largest Open Access journal publishers. It is currently publishing more than 200 open access, online, peer-reviewed journals covering a wide range of academic disciplines. SCIRP serves the worldwide academic communities and contributes to the progress and application of science with its publication.

Other selected journals from SCIRP are listed as below. Submit your manuscript to us via either submit@scirp.org or Online Submission Portal.
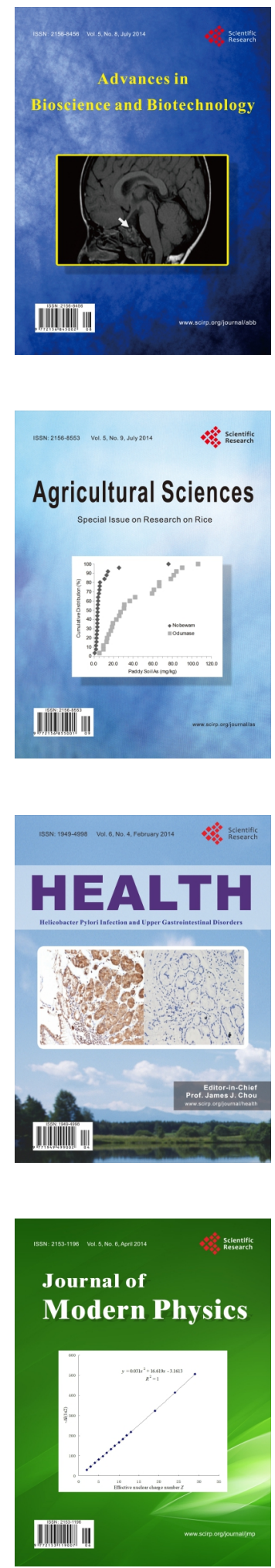
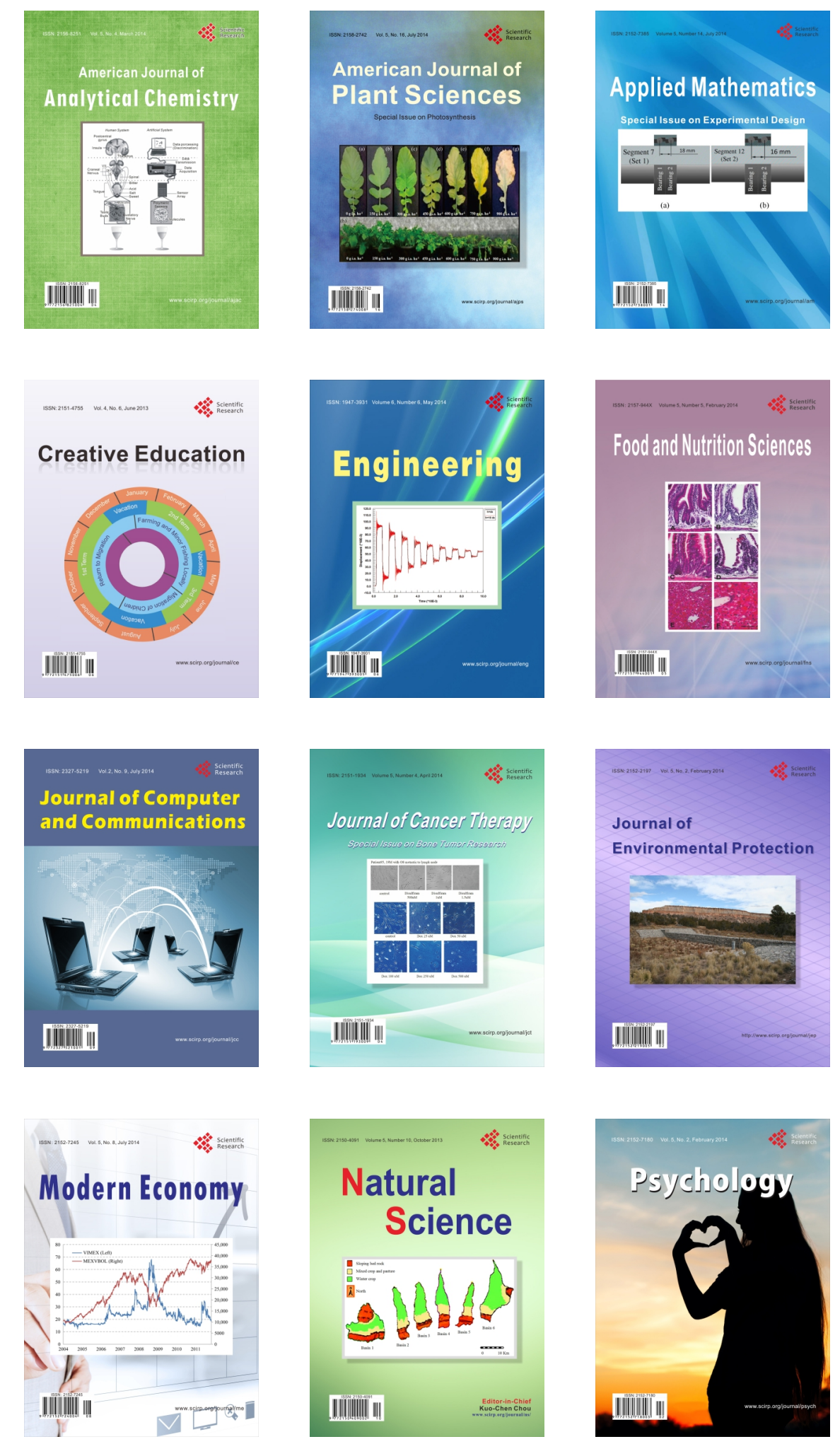